\title{
Editorials
}

\section{Quality of nursing: a European perspective}

Clinical audit; peer review; accreditation; and structure, process, outcome would have been the focus of this article if it had been written a year ago. Today, working in the European regional office of the World Health Organisation, I find that my preoccupations are rather different. As I survey the new world order from my eyrie in Copenhagen those fierce debates and theological hair splitting about whose standard setting method is the "best" or about the meaning of the latest jargon seem the luxuries of a privileged few. For me the major quality issues now include hospitals with no running water, babies dying of malnutrition, and antibiotics long past their sell by date - issues arising not only in the Third World but in our own front garden.

The travel which has broadened my mind since I became WHO Europe's regional adviser for nursing in mid-1991 focuses on the countries of central and eastern Europe, named as priorities by our own member states. I have seen for myself something of the current conditions in Hungary, Romania, and Russia and heard much more from colleagues in other countries (and also encountered an assortment of health service gurus busily trying to convert their white paper currency into hard European currency units (ecus) as they extend their knowhow across the ruins of the Berlin Wall). What conclusions have emerged? It is clearly dangerous to generalise about countries of such cultural, social, and developmental diversity, and few things infuriate them more than being lumped together. Yet it is undeniable that millions of Europeans are in poor health and that their health services are incapable of responding anything like adequately to the challenge.

The state of nursing in central and eastern Europe is both an illustration and a cause of this crisis. British nurses, despite their great strides in recent years - not least in quality assurance - still complain, and quite rightly, about lack of status and recognition, but the contrast with their European sisters is startling. In some countries the relation between being cared for, feeling better, and getting better is simply not mentioned, let alone recognised. Most eastern European nurses are low paid skivvies carrying out doctors' orders. Their humane acts of love and care have no legitimate place: they happen despite, not because of, the system. If nurses are taught anything it is secondhand medicine by doctors who cannot find another job. Impoverished, unhealthy, and overworked women struggling to provide for their own families, nurses usually have little love left over for their patients, let alone for themselves. The plight of the Romanian children is the most graphic but by no means the only example of the consequences.

What, then, has quality to do with all this? It is really a matter of fish and fishing. I was reminded of this Chinese proverb by Klára Sövényi, chief nurse of Hungary, when asked what help offered by the richer countries could possibly make any difference to the quality of Hungarian nursing. She replied that people who are hungry need to eat, so giving them fish will help to ease their hunger. But what then? Either they will continue to depend on you for food or they will go hungry the next day, and the next - unless you teach them how to catch their own fish. The "fish" that nurses are requesting in central and eastern Europe to help them to do their jobs properly includes basics such as medicines, supplies, equipment, and decent food for their patients. They are also articulating clear demands for the "fishing tackle" which will enable them to build better services for the future. These requests range from radical new curricula, management development, and a more sensible division of labour through to more prosaic but equally compelling needs for textbooks, journals, and even pencils and paper to write their own notes.

Unless your compassion fatigue is acute it is hard to resist the temptation to ransack your own bookshelves and stationery cupboard or hold a jumble sale. WHO's response, however, has to be different. As a policy and development agency it cannot provide much instant aid; instead it concentrates on the less immediate but equally crucial "angling techniques." The problems of mobilising resources and making sure they reach their proper destination are immense but so are the opportunities for significant intervention. Health and health care ride high on political agendas, as all the former Communist countries are trying in some way to reform and rebuild their health systems. Amid economic chaos and political instability the siren calls of the market place, "privatisation," and the rest are ill understood but seductive: the risks of failure are great but so are the opportunities for change.

Nurses and others who are relatively immune to the sirens usually recognise that long term, sustainable improvements in health services are impossible without individual and collective development through education in its broadest sense. They usually put the reform of basic nursing education at the top of the list, closely followed by training in clinical practice, management, and research. Yet the outlook is bleak if their own governments prove as slow to invest in the nursing infrastructure as the British government has been, though its recent record is better. Where a system is being rebuilt virtually from scratch there is a real but elusive opportunity to take a more than rhetorical interest in health outcomes, primary health care, and the cost effectiveness of high quality nursing.

In such a context success stories from other systems can be explored and adapted. Just as importantly, the potential of the often unrecognised skills and ideas of the service's own staff can be set free, often through relatively simple methods based on building self esteem and confidence (provided that the instructor's main interest does not lie in walking off with the prize catch). Fancy tackle and waders are little use if you can only afford a string and a pin, but principles, expertise, and attitudes can be shared fairly cheaply.

Some of the quality assurance approaches which have worked best in British nursing could be adapted and used. Those approaches which pay due attention, unfashionably but wisely, to process as well as outcome have most to offer as they tend to encourage maximum participation and local ownership - in other words they understand what motivates people, which is the only secure foundation for positive long term results. 
Systematic methods such as organisational audit can help to establish standards and review processes in a fledgling service, through reaching a consensus about priorities and introducing ways of assessing progress instead of being overwhelmed by demands and needs or swamped by offers of help of the wrong type. More modest beginnings in quality circles and peer review can enhance the efforts of small groups of drivers of change, helping them to develop teamwork and gain confidence through local successes.

None of this will progress far without an initial supply of resources. If relief efforts are disinterested, well planned, and well executed there may be some hope of success, although the record from other parts of the globe is depressing. In my experience to date, the motivation to learn and develop from a very low baseline is perhaps the most striking attribute of nurses in the exCommunist countries. Also their requirements may not be that different from those of nurses in the United Kingdom. Wherever they are introduced, quality assurance methods which are designed to be an integral mechanism of service development have to be simple, accessible, cheap, effective, and attractive. Perhaps the worlds of nurses are not as far apart as they seem - it is more a matter of degree. We have just as much to learn as we have to teach.

Regional Adviser for Nursing, Midwifery,

JANE SALVAGE and Social Work,

WHO Regional Office for Europe,

DK-2100 Copenhagen, Denmark
Arnold Relman called the new emphasis on patients' outcomes a revolution in medical care. ${ }^{1}$ The main activity to which he referred was the systematic study of the relation between health care and its consequence. The aim in the United States was to provide a rational basis for improving the effectiveness and efficiency of the health care system and to reverse incentives which had for many years encouraged inappropriate overuse, particularly of inpatient procedures and high technology care. The objective was not cost containment but quality improvement, although increased costs might have accrued if the results identified underuse of appropriate services by high risk populations and led to recommendations and guidelines requiring increased expenditure to improve access and outcomes.

The equivalent revolution - despite a brief pause for the democratic electoral process - is being felt on this side of the Atlantic. The popular cause for greater public accountability of the health service and for measures which enable patients and carers to judge the quality of care according to their improved health is being championed by consumer groups but also has the broad support of an alliance of researchers, social scientists, doctors, other health professionals, and managers.

The leaves only the status quo as the redoubtable combatant. Yet in this headlong rush to reorientate the NHS towards health and not just health care it may be worth asking what are the main aims, who should take responsibility for this new development, and how can it work in practice?

The outcomes under consideration are those objectively measured consequences of treatment that have been traditionally used, such as mortality; morbidity; complications and readmissions; clinical assessment, such as physiological functioning; measures of patients' expectations, values, and preferences; and functional health status (quality of life).

There are three main questions:

(1) Whether an intervention should be undertaken at all - would it make any difference to the outcome compared with no intervention?

(2) How are choices made between different options to achieve the desired outcomes?

(3) How are patients' values included in determining desired outcomes and choice of treatment?

But problems arise when practical solutions are sought. The outcomes of many health care interventions are not well understood, and the scientific basis of the health services as constituted up until the reforms of 1991 has not sought to understand or value the outcome equivalent of its investment. The result is few available measures for assessing the consequences of health care interventions and no or little commitment to their development. Information systems are not geared up to collect suitable information, and neither patients nor professionals are expected to value health care in terms of its output. The tribal boundaries drawn between the different health care sectors compounds the problem. There are few, if any, examples of standardised data collection between primary and secondary health care practitioners which would allow an assessment of patient outcomes that link patient contacts with all providers, particularly general practitioners and hospital specialists. Finding the perfect health outcome measures does not therefore rely solely on adequate psychometric validation of specific instruments. It requires that the aims of health care are made explicit and agreed between all those involved in the care of the patient who are likely to influence the outcome. It also requires that substantial incentives are generated for collecting and using information on outcomes. This means that the information should have clinical utility, be central to decision making by management, and enable patients to judge the merits of the treatment they have received.

The answers to the questions are not a simple matter of testing hypotheses; they need to overcome a complex system of health care, which has come to rely on anecdote, best guesses, and tradition as the underlying reasons for many interventions and which assumes that doctors' values are a proxy for patients' values and that patients neither have the technical knowledge nor inclination to comment on clinical matters.

The intellectual climate surrounding the development of a market in health care is focusing attention on the need to grasp these issues. The consumer in the market place will need to be better informed. Service providers have a responsibility to correct the asymmetry of information between patient and professional so that consumer demand can be the arbiter of good and poor quality or distinguish desirable from undesirable practice. A system of health care led by need can function only if it finds a way of valuing and measuring health outcomes.

The drive for efficiency in the Health of the Nation green paper will contribute significantly to the initiative regarding outcomes. Although not explicitly discussed in 